\title{
UM EXEMPLO DE IRONIA SOCRÁTICA NO ÍON DE PLATÃO
}

Teodoro Rennó Assunção*
* Faculdade de Letras da UFMG.

RESUMO: A partir da informação básica sobre a história do conceito de "ironia", assim como da definição de "ironia socrática” por Gregory Vlastos em seu conhecido artigo "Socratic Irony", este nosso breve artigo visa a fazer simplesmente um teste da proposição de G. Vlastos através de um estudo de caso da ironia socrática, comentando o seu exemplo mais importante em um diálogo menor de Platão: o Íon.

PALAVRAS-CHAVE: ironia; ironia socrática; Vlastos; exemplo; Íon de Platão.

\section{UN EXEMPLE D'IRONIE SOCRATIQUE DANS L'ION DE PLATON}

RÉSUMÉ: A partir de l'information (de base) sur l'histoire du concept d'“ironie", ainsi que de la définition d"“ironie socratique" par Gregory Vlastos dans l'article déjà célèbre "Socratic Irony", notre bref article essaie simplement d'éprouver la proposition de G. Vlastos au moyen d'une étude de cas de l'ironie socratique, dont l'objet est son exemple le plus important dans un dialogue mineur de Platon: l'Ion.

MOTS-CLÉS: ironie; ironie socratique; Vlastos; exemple; l'Ion de Platon.

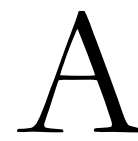

ntes do que uma discussão direta da definição de ironia socrática por Gregory Vlastos em seu conhecido artigo "Socratic Irony" (VLASTOS, 1987), do qual me servi como fonte de informação bem organizada sobre a história do conceito de "ironia", o que tentarei fazer aqui é simplesmente um teste da sua proposição através de um estudo de caso da ironia socrática, comentando o seu exemplo mais importante em um diálogo menor de Platão: o Íon, onde por sinal o termo mesmo eip seus cognatos) jamais aparece.

Mas, apenas para introduzir o tema, tentarei delinear muito resumidamente a proposição de G. Vlastos. Ele começa citando a definição de Quintiliano, pois ela serviria de base a uma definição moderna do termo (tal como dicionarizada, por exemplo, no Webster's): "Ironia" é a figura de linguagem ou tropo "em que é para 
ser compreendida alguma coisa contrária à que é dita" ("contrarium ei quod dicitur intelligendum est”, Quintiliano, Institutio oratoria 9. 22. 44, apud VLASTOS, 1987, p. 79). No Webster's, esta definição ganha apenas uma maior amplitude: "Ironia é o uso de palavras para expressar alguma coisa diferente do que, e especialmente oposta a, seu significado literal."1 Mas, como os seus três primeiros exemplos triviais demonstram, para que a ironia seja compreendida (ou seja: para que ela seja efetivada ou aconteça), é preciso que quem a ouve seja capaz de detectar minimamente esta alguma coisa diferente de ou oposta ao sentido literal do que está sendo dito, porque, se não, ele será meramente enganado, o que não seria o propósito elementar da ironia. Alguma diferença pode, no entanto, vir a acontecer nas ironias, segundo a maior ou menor clareza (para o ouvinte) da indicação desta alguma coisa diferente de ou oposta ao sentido literal do que está sendo dito, havendo assim algum risco, no caso da não clareza de uma ironia mais sutil ou enigmática, de que esta não venha a acontecer (o que não modificaria, porém, a intenção primeira de não enganar de quem a formula).

Ora, para a surpresa de quem pensa a ironia segundo esta definição, o sentido

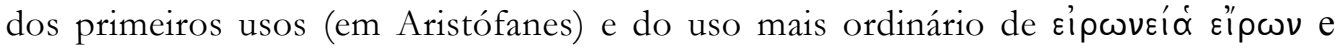

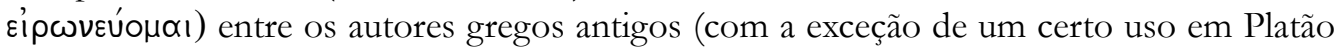
e na Retórica a Alexandre) é o de fingimento e falsificação, com uma intenção deliberada de enganar (o que, em princípio, desqualificaria moralmente o seu usuário). A proposição central da breve história da "ironia" por G. Vlastos é a de que a passagem do primeiro para o segundo e moderno sentido do termo teria sido uma operação efetuada por Sócrates, ou - para ser mais preciso - pelo Sócrates platônico (ainda que o Sócrates de Xenofonte às vezes também proceda assim). Se a intenção do Sócrates platônico não é obviamente a de enganar (ainda que contenha uma dose de humor que faz alguma troça do seu interlocutor), ela deve estar dirigida a um esclarecimento ou à abertura de um processo de conhecimento para o seu ouvinte.

O que, porém, nem a definição de Quintiliano nem a, bem próxima dela, da

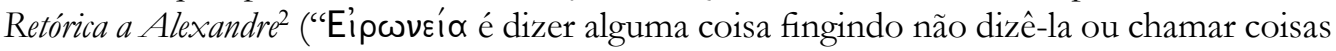
pelos nomes contrários", Retórica a Alexandre, XXI, 1434a 17-19) implicam - e que parece importante também para a ironia socrática (apesar de Vlastos não destacá-lo suficientemente) - é o elemento da auto-depreciação, característico do tipo moral ou caráter do Elp $\omega v$ ("o fingidor" ou "farsante"), presente tanto no retrato que faz dele Aristóteles no livro IV da Ética a Nicômaco quanto Teofrasto logo no começo d'Os caracteres ("A então, para apreendê-la num traço, um fingimento - para pior - das ações e das palavras", Os caracteres 1, 1; TEOFRASTO, o sublinhado é meu), ainda que a visão de Aristóteles seja mais

\footnotetext{
1 "Irony is the use of words to express something other than, and specially the opposite of, [their] literal meaning (Webster's).” (VLASTOS, 1987, p. 79).

${ }^{2}$ Seria útil sinalizar aqui apenas que este tratado, que durante muito tempo foi atribuído a Aristóteles, foi por H. Rackham atribuído a Anaxímenes de Lâmpsaco (cf. RACKHAM, 1965, p. 258-262), o que Vlastos não considera certo tampouco, notando somente que o seu "ambiente linguístico-político" é o da Atenas do século quarto, tendo alguma semelhança com a Arte retórica de Isócrates (cf. VLASTOS, 1987, p. 82-83, n. 15).
} 
branda e nuançada do que a de Teofrasto. Em vista do Íon, seria útil aqui lembrar (o que não faz Vlastos) que em Aristóteles o eip um tipo extremo, cujo oposto também extremo é o $\alpha \lambda \alpha \zeta \omega$ ' ("fanfarrão", que se apresenta como melhor do que realmente é), o meio termo adequado e elogiável sendo o homem verídico (que se apresenta como realmente é). Neste caso, porém, o tipo extremo menos

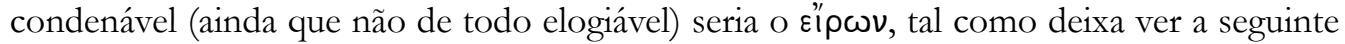
(e moralmente arguta) passagem: "Os auto-depreciadores ( $\varepsilon$ " $\rho \omega \nu \varepsilon S$ ), que subestimam os próprios méritos, são mais graciosos quanto aos costumes, pois parecem falar assim não por causa do ganho, mas para evitar a ostentação. E estes negam, sobretudo, as coisas tidas como bem reputadas, como também Sócrates fazia." (ARISTÓTELES. Ética a Nicômaco 1127 a 23-26).

Finalmente, apenas como um exemplo desta auto-depreciação irônica no Sócrates platônico (já que não discutirei os exemplos mais difíceis e decisivos comentados por Vlastos, como o da fala de Alcibíades no Banquete), exemplo que permite também introduzir esquematicamente a categoria de "ironia complexa" proposta por Vlastos, vale lembrar a dupla e paradoxal alegação socrática (em Platão) de que ele não conheceria nem ensinaria nada, o que seria para ser tomado literalmente no sentido tradicional de conhecimento e ensino (como respectivamente certeza no campo moral e transmissão direta de conhecimento), mas de modo figurado em um outro e mais alto sentido socrático (como respectivamente crença justificada pelo método do argumento elênctico e possibilitação da descoberta da verdade pelo próprio suposto discípulo).

Feita, então, esta brevíssima introdução do tema a partir de Vlastos, passo agora - para testá-lo e alargar o seu repertório - à citação e ao comentário do primeiro (de dois) e decisivo exemplo de uma bem reconhecível ironia socrática no Íon de Platão, que (como primeiro exercício interpretativo) me propus traduzir: ${ }^{3}$

Sócrates - De fato, Íon, muitas vezes eu vos invejei, a vós rapsodos, por vossa arte; pois é invejável o fato de, por um lado, convir à vossa arte ter sempre o corpo adornado e vos mostrar os mais belos que é possível, e, por outro, o de vos ser necessário frequentar [i.e. passar o tempo com] vários e bons poetas [i.e. compositores], e sobretudo Homero, o melhor e mais divino dos poetas, e conhecer a fundo o pensamento dele, e não apenas os versos. Pois alguém não seria rapsodo, se não compreendesse o que é dito pelo poeta. É preciso, pois, que o rapsodo seja o intérprete do pensamento do poeta para

\footnotetext{
${ }^{3}$ Adoto o texto grego estabelecido por Penelope Murray no volume Plato on Poetry da "Cambridge Greek and Latin Classics” (MURRAY, 1997, p. 37-50), cotejado com o texto grego estabelecido por Louis Méridier no tomo V, 1 da edição das obras completas de Platão da "Belles Lettres" (1989, p. 29-47). Foram consultadas as traduções de L. Méridier (ibidem) e Monique Canto para o francês (1989, p. 85-129), a de W. R. M. Lamb para o inglês (1995, p. 406-447), e a de André Malta para o português $(2007$, p. 21-53).
} 
os ouvintes. Mas é impossível que o faça bem aquele que não sabe o que quer dizer o poeta. Todas estas coisas, então, são dignas de serem invejadas.

Íon - Dizes a verdade, Sócrates. A mim, ao menos, isso fornece o maior trabalho desta arte. E creio que digo, dentre os homens, as mais belas coisas sobre Homero, de modo que nem Metrodoro o Lampsaquense, nem Estesímbroto o Tássio, nem Gláucon, nem nenhum outro dos que um dia existiram foi capaz de dizer tantos e tão belos pensamentos sobre Homero quantos eu (digo).

Sócrates - Dizes bem, Íon. É claro, pois, que não te recusarás a mostrá-lo para mim.

Íon - De fato, Sócrates, é digno de se ouvir como eu tenho bem adornado [ou ordenado] Homero; de forma tal que creio que sou digno de ser coroado com uma coroa de ouro pelos Homéridas.

(Ion 530 b-d; 1997, p. 37)

Certamente não passou despercebido aos comentadores o quanto esta primeira fala de Sócrates - decisiva porque define, segundo seus próprios termos, a função mais importante do rapsodo (definição à qual aquiescerá Íon), orientando o curso ulterior do diálogo - pode ser definida como um exemplo emblemático de ironia (socrática), já que ela se organiza a partir do reconhecimento da inveja que ele tem dos rapsodos, o que a princípio implicaria a sua inferioridade em relação a eles (sendo ela, pois, auto-depreciativa), mas deixando também adivinhar o quanto o pretenso elogio aos rapsodos encobre uma crítica de suas práticas (ou seja: o quanto ele estaria querendo dizer outra coisa ou o contrário do que ele literalmente diz).

No entanto, o conjunto desta fala irônica de Sócrates não foi analisado com o cuidado devido para nela se determinar com precisão o que deve ser compreendido de outro modo (isto é, como crítica) e o que eventualmente pode ser compreendido de modo literal (ou de modo também literal). Pois o que se apresenta como invejável nos rapsodos não é algo simples, mas duplo ou mesmo triplo. Primeiramente, Sócrates diz para Íon ser invejável "o fato de convir à vossa arte ter sempre o corpo adornado e vos mostrar os mais belos que é possível", ou seja: a conveniência - dado o caráter público de suas apresentações ou performances (por exemplo, os concursos de rapsodos no festival de Asclépios em Epidauro ou nas Panatenéias em Atenas) - de uma bela indumentária e de uma bela aparência. Mas, pelo que a sequência do diálogo nos revela, somos levados a duvidar de que o adorno do corpo seja de fato o resultado de uma arte ( $T \dot{X} \times \nu \eta)$ ou mesmo, como a sequência desta mesma fala esclarece, que ele possa ser considerado como um elemento que define substancialmente a atividade do rapsodo. O cuidado excessivo com a aparência será assim confirmado como uma espécie de superficialidade que condiz bem com a falta de inteligência lógica (ou estupidez) deste rapsodo que é Íon. Pode-se, portanto, neste primeiro caso, dizer que Sócrates está sendo irônico, pois o seu pretenso elogio à indumentária e à bela aparência de Íon (como representante dos rapsodos) deixa entrever uma crítica que a sequência do diálogo fará ver mais claramente. 
O segundo fato invejável nos rapsodos é, por sua vez, desdobrado em dois (que seriam, ao que parece, complementares): o primeiro seria o de ser necessário "passar o tempo

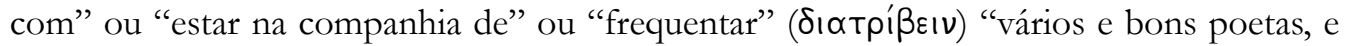
sobretudo Homero, o melhor e mais divino deles"; o segundo o de (ser necessário) "conhecer

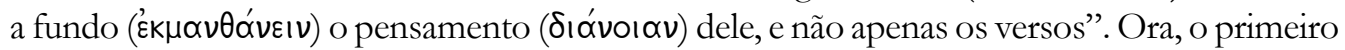
elemento deste segundo fato poderia, desde que não condicionado pelo segundo e tomado absolutamente, ser suspeito de estar sendo criticado por Sócrates (mesmo que ele demonstre depois, por seu conhecimento da Ilíada e da Odisseia, o quanto ele frequentou Homero), já que o próprio diálogo como um conjunto constitui um exercício filosófico de investigação dialética que não coincide com a mera frequentação de "vários e bons poetas e sobretudo Homero", mesmo que use criticamente citações deste último como exemplos de descrições de "artes" cuja precisão ou boa composição cabe em cada caso ao especialista em tal arte, ou seja: ao que a conhece bem, julgar (no que é também a proposição de um critério crítico ou interpretativo de caráter mais geral).

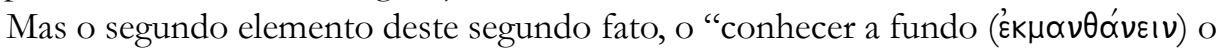

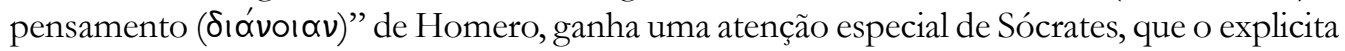
como operação interpretativa ou exegética (isto é, crítica) necessária e como condição sine qua non para se ser rapsodo, ${ }^{4}$ fazendo assim (bem socraticamente) do comentário crítico - e não da mera memória e recitação - a parte mais importante da atividade do rapsodo. A $\delta ı \alpha ́ v o ı \alpha \nu$, que traduzimos aqui por "pensamento", tem seu sentido explicitado tanto pela

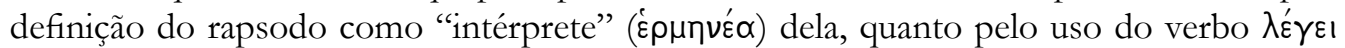
com o sentido, tal como o entendemos aqui, de "quer dizer" (cf. L. Méridier e M. Canto, "veut dire", e W. R. M. Lamb, "means" ), ou seja: ela é "o que quer dizer o poeta" - donde a sua possível tradução por "intenção", segundo uma sugestão de G. Nagy (para aproximar o sentido platônico-socrático especializado de "intelecto" do mais genérico de "pensamento" como "intenção" ou "propósito", segundo o Greek-English Lexicon de Liddell-Scott-Jones; cf. NAGY, 2002, p. 29-30) - e, por isso, demanda um trabalho de interpretação.

É esta proposição de Sócrates - que poderia estranhar os que imaginam os rapsodos apenas como recitadores, mas que é facilmente aceita por Íon - que será testada na segunda parte do diálogo, quando Sócrates questionará Íon sobre a melhor maneira de ler as passagens de Homero $\operatorname{citadas}^{6}$ que tratam das artes da condução de carros, da medicina, da pesca e da

\footnotetext{
4 "Pois alguém não seria rapsodo, se não compreendesse o que é dito pelo poeta. É preciso, pois, que o rapsodo seja o intérprete do pensamento do poeta para os ouvintes."

${ }^{5}$ Ver respectivamente nas traduções já citadas de L. Méridier (1989, p. 30), de M. Canto (1989, p. 87) e de W. R. M. Lamb (1995, p. 409).

${ }^{6}$ Para uma análise detalhada das eventuais diferenças entre o texto de Homero tal como citado por Íon ou por Sócrates no Íon e o texto de Homero tal como estabelecido pelos editores a partir dos manuscritos, fenômeno não desprezível para quem quer pensar os modos de transmissão do texto homérico, ver o já clássico L'Homère de Platon de Jules Labarbe (LABARBE, 1949, p. 88-136). Obviamente o entendimento mesmo destas passagens nos conjuntos narrativos maiores da Ilíada e da Odisseia (dos quais elas fazem parte e sem os quais elas não podem ser devidamente compreendidas) não
} 
adivinhação, ${ }^{7}$ sugerindo que em cada caso é o conhecedor da arte em questão (o cocheiro, o médico, o pescador e o adivinho) - e não o rapsodo - aquele que saberá se Homero compôs bem ou não a descrição discursiva desta arte. Em cada um destes quatro casos (assim como em todo o diálogo) Íon não exercerá a sua função de comentador ou, nos termos de Sócrates, "de intérprete do pensamento de Homero", pois ele reconhece que aquele que pode de fato fazê-lo é o especialista em cada uma destas quatro artes.

Curiosamente, quando perguntado por Sócrates sobre as passagens de Homero que descreveriam a arte em que ele é especialista, ou seja: a arte do rapsodo (que de fato não está, enquanto tal, representada em Homero), Íon não pensa em momento algum citar as passagens que descrevem a atividade daquele que por função está mais próximo do rapsodo nos poemas homéricos: o aedo, cujos exemplos mais diretos são Fêmio e Demódoco na Odisseia, e cuja arte, como a de Homero, poderia ser definida como a da narrativa em versos (que Íon, já sem o acompanhamento da lira, pode apenas recitar de cor e depois comentar), preferindo dizer, imediatamente e sem pensar, que todas, já que ele as conhece todas de cor, como se a sua memorização lhe desse a ilusão de um domínio (ou saber) de fato sobre os seus conteúdos, confusão que - dado o básico papel formador da poesia homérica na Grécia do último quarto do século V a.C. (data dramática aproximativa do diálogo) - deveria ser bastante comum nesta época e, portanto, passível de uma crítica gnoseológica por parte da filosofia.

Por outro lado, quando Íon tenta definir de modo genérico o que, excluindo as artes específicas, o rapsodo sabe, isto é: a capacidade discursiva adequada às diferentes funções sociais básicas (a do homem e a da mulher, a do escravo e a do homem livre, a do governante e a do governado), como se ele fosse um professor de oratória ou um sofista, Sócrates dissolve a generalidade vazia deste pretenso saber discursivo, remetendo em cada caso o conteúdo do discurso ao saber específico em questão, por exemplo: o do que governa ou comanda um navio no mar, quando este é atingido por uma tempestade, como devendo ser a capacidade discursiva de um navegador apto a julgar o que deve ser feito nesta situação específica.

é uma questão que se coloca para Sócrates que, neste diálogo, as cita sem nenhuma contextualização e apenas como exemplos conhecidos de saberes práticos (como se Homero, antes do que narrativas unas, constituísse de fato uma espécie de "enciclopédia" formativa para os atenienses desta época). ${ }^{7} \mathrm{Na}$ Odisseia (XVII, 383-385) temos uma breve listagem dos "que exercem uma atividade para a

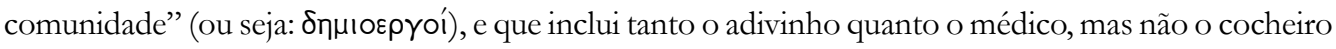
ou o pescador, e que traz ainda o carpinteiro e o "divino aedo" (em destaque por ser o único a receber um verso inteiro), que estão ausentes do conjunto de exemplos homéricos de Sócrates (o que antecipa, no caso do aedo, o esquecimento de Íon em relação a esta atividade ou saber homérico que tem um certo destaque na Odisseia). Ao fazer esta referência a esta conhecida passagem da Odisseia, Penelope Murray comenta: "Cf. HOMER. Od. 17.383-385 where seer, physician, carpenter, and 'divinely inspired' bard are listed as $\delta \eta \mu$ ı pүoí. The latter is, of course, omitted from S.'s list here. Cicero, when looking for parallels to the art of divination, speaks of the physician, the pilot, the general and the statesman as typical examples of craftsmen. See De div. I.24 (...) and De nat. deor. 3.76." (PLATO, 1997, p. 127). 
E se a especialização é uma necessidade para uma justa apreciação (de um objeto ou atividade), a multiplicidade de saberes (ou artes) presentes nos dois poemas de Homero torna de algum modo impossível a função do rapsodo como comentador crítico deste conteúdo múltiplo, o que, no entanto, não retira legitimidade à exigência de "conhecer a fundo

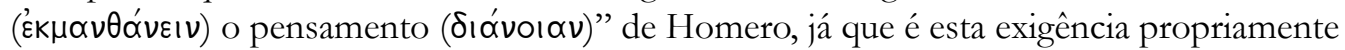
filosófica o que leva Sócrates a estabelecer um princípio de compreensão ou juízo para o que o poeta diz. Aqui, portanto, a ironia de Sócrates é mais sutil (podendo talvez ser pensada como uma ironia complexa, segundo a categorização de Vlastos), pois ele não estaria criticando em si o que ele mesmo postula filosoficamente como condição sine qua non para se ser rapsodo, o "conhecer a fundo o pensamento" do poeta (aqui Homero), e sim a incapacidade (ou impossibilidade) de Íon ou de um outro rapsodo qualquer exercê-lo com competência, o que, porém, acaba resultando no reconhecimento lógico da inexistência da arte mais essencial do rapsodo, a do comentário crítico (já que um indivíduo único não poderia conhecer por experiência as múltiplas artes e domínios de saber descritos nos poemas homéricos).

É, portanto, retrospectivamente apenas (já que é o próprio desenrolar do diálogo que o revela) que pode ser compreendida em sua inteireza a ironia de Sócrates ao fazer este elogio liminar da arte do rapsodo, no que é também a ocasião para uma astuciosa primeira definição desta arte, orientando a sequência do diálogo. Pois se a crítica da bela aparência do rapsodo (como uma possível arte) já se torna manifesta pelo modo como é definida essencialmente a arte do rapsodo no fim desta mesma fala de Sócrates (como a arte da interpretação do pensamento do poeta), a crítica do rapsodo como um intérprete do pensamento do poeta (no caso, Homero) só será efetivada quando for demonstrada a impossibilidade de um indivíduo único (e sem uma competência específica) conhecer a fundo as múltiplas artes e domínios de saber descritos nos poemas homéricos.

Se, a partir da Apologia de Sócrates, a investigação do pretenso saber do rapsodo pode ser pensada como uma das investigações dos pretensos saberes públicos (como o do político, o do poeta ou o do adivinho) feitas por Sócrates para compreender a asserção délfica que dizia ser ele o homem mais sábio (por ser o único, como ele compreenderá mais tarde, a saber que é ignorante, enquanto os outros pretendem saber o que na realidade ignoram), no Íon, Sócrates não pretenderá em nenhum momento "conhecer a fundo o pensamento do poeta Homero" (mesmo que ele demonstre uma capacidade de memória e recitação de Homero igual ou superior à de Íon), mas será capaz de indicar o princípio que deve nortear a interpretação do que o poeta diz (ou seja: conhecer bem o assunto em cada caso), e, uma vez reconhecida a partir dele a impossibilidade de um só ser humano interpretar bem o conjunto do que é dito por Homero, ele irá chegar à conclusão - do ponto de vista lógico, destruidora para um rapsodo - de que sua arte não é possível ou não existe. Uma tal ironia retrospectiva ridiculariza a pretensão deste saber de Íon intérprete do pensamento de Homero como absurda, e implicaria, no caso de um reconhecimento direto e consequente por parte de Íon, simplesmente o abandono desta profissão ou atividade por definição impossível, o que certamente não é simples para um rapsodo. Deve-se admitir que a possível intenção educativa da ironia socrática é, neste caso, demasiado pesada para seu interlocutor, que 
também não poderia percebê-la imediatamente, devendo assim ser deslocada (com mais verossimilhança) para o leitor do diálogo.

A resposta de Íon começa por uma aquiescência imediata ("Dizes a verdade, Sócrates.") à última e substancial definição da atividade do rapsodo por Sócrates (o "conhecer a fundo o pensamento" do poeta, isto é: ser dele o intérprete) como sendo aquilo que lhe "fornece o maior trabalho desta arte", ou seja: como algo difícil e nuclear em sua atividade (definida como T'́x $\dot{v} \eta$, “arte”), mas de que ele é capaz. Mas Íon, deixando de lado a memória e recitação (“o saber apenas os versos do poeta”), não se preocupa em discutir o sentido preciso da função crítico-interpretativa segundo os termos da proposição de Sócrates, e parece não perceber que com isso ele os está tacitamente aceitando, o que implica aceitar também que eles definam as coordenadas desta investigação em forma de diálogo. Para usar uma imagem de caça, é como se ele tivesse mordido a isca que astuciosamente lhe lança Sócrates, o que lhe será fatal.

Íon, desavisado e confiante, sugere então exemplos de intérpretes do pensamento de Homero (Metrodoro, Estesímbroto e Gláucon) que, pelo pouco que deles sabemos, poderiam delimitar ao menos um modo de interpretação de Homero, que ele não se preocupa na sequência em definir, mas no qual ele seria o melhor (sendo menos plausível a hipótese de que ele fosse o melhor justamente por exercer um outro modo de interpretação). A formulação "dizer as mais belas coisas ou tantos e tão belos pensamentos sobre Homero" enuncia dois objetos marcados pela beleza (que, porém, não será definida): o primeiro mais

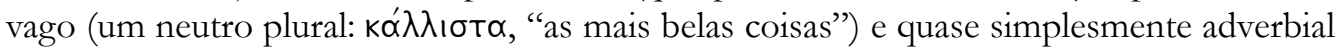
("o mais belamente"), o segundo mais preciso ("tantos e tão belos pensamentos"), ainda que tão pouco fiquemos sabendo com precisão o que seriam para Íon estes "pensamentos"

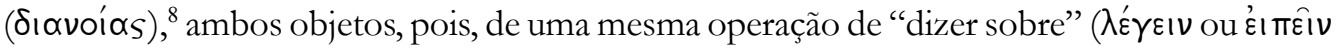
пєрí) que não poderia ser compreendida senão como "um comentário ou uma explicação sobre", no caso, "Homero" ('Ouńpou), do mesmo tipo (ou no mesmo modo) dos feitos por Metrodoro, Estesímbroto e Gláucon, ainda que este tipo ou modo não seja definido nem exemplificado.

O pouco que se sabe sobre estes "intérpretes de Homero" (que tenderíamos a denominar mais como "filósofos" ou "sofistas" do que como "rapsodos") foi reunido criticamente por Nicholas J. Richardson no conhecido artigo "Homeric professors in the

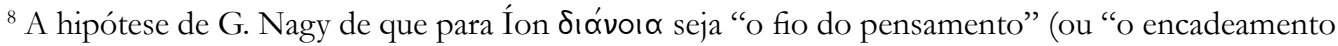
da narrativa"), "train of thought", no caso, de Homero, supõe que o rapsodo possa se identificar com este fio de modo a poder citá-lo também como comentário sobre o mesmo Homero ["Since the rapsode can become part of Homer's train of thougth, of Homer's dianoia, he can also tell the thougts of Homer as a verbal commentary (i.e., not necessarily a written commentary) about Homer (...).” (NAGY, 2002, p. 29)], e não só permanece inverificada pela ausência de exemplos, como tornase improvável com a citação dos nomes de Metrodoro, Estesímbroto e Gláucon, que dificilmente fariam comentários sobre Homero apenas citando-o.
} 
age of sophists" (RICHARDSON, 1975). ${ }^{9}$ De Metrodoro, um discípulo de Anaxágoras, sabe-se de uma leitura alegórica da Ilíada em que os heróis seriam representações simbólicas de partes do universo, e os deuses, de partes do corpo humano (por exemplo, Agamêmnon representando o "éter", Aquiles o sol, Helena a terra, Páris o ar, Heitor a lua, enquanto Démeter representaria o fígado, Dioniso o baço e Apolo a bile). Mas ele teria também feito interpretação linguística de termos de sentido ambíguo (como $\pi \lambda \lambda^{\prime} \omega \nu$ na Ilíada X, 252-253, que pode querer dizer tanto "cheio" quanto "mais"). Chama a atenção o fato de que se Íon, citando Metrodoro, está se referindo a uma interpretação alegórica de Homero, ele não use para designá-la o termo úmóvoı́, literalmente "pensamento ou sentido subjacente", também comumente traduzido por "alegoria”, que aparece no livro II da República (378 d) para designar um "sentido subjacente" ou "alegórico", que o jovem seria incapaz de decifrar, em cenas homéricas de lutas entre deuses como a de Hera sendo agrilhoada pelo filho ou a de Hefesto sendo arremessado (do Olimpo) pelo pai.

Já de Estesímbroto sabe-se pelos escólios da Ilíada de três interpretações suas de passagens problemáticas deste poema, interpretações que não trazem, porém, nenhuma leitura de tipo alegórico como as de Metrodoro, mas são antes uma espécie de crítica textual ou lexicográfica. A primeira, por exemplo, quer explicar o problema de como Nestor o ancião podia levantar sua taça enquanto outros teriam dificuldade em fazê-lo (cf. Il. XI, 636-367), dizendo que Nestor o fazia, "de modo a que ele pudesse plausivelmente parecer ter vivido muitos anos: pois se sua força permanece e não foi esgotada pela velhice, é razoável que a extensão de sua vida estivesse em acordo com isso." (Cf. RICHARDSON, 1975, p. 72). A terceira quer explicar o verso 76 do canto XXI da Ilíada em que Licáon diz para Aquiles

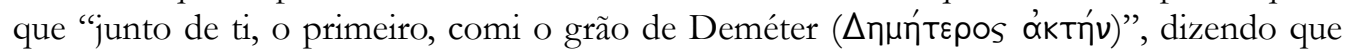
"Licáon era um estrangeiro, e assim ele tinha comido somente farinha de cevada grosseira

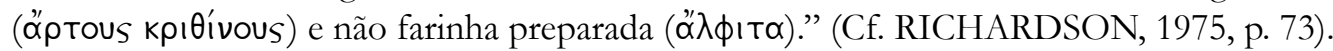

Enfim, de Gláucon sabe-se apenas, caso ele seja o Gláucon citado por Aristóteles no capítulo 25 da Poética, que um princípio crítico bastante razoável inferido a partir dele por Aristóteles é o de que "se o nome contém uma significação contraditória, é mister procurar quantos significados ele pode assumir na frase em questão. Por exemplo, em 'por ela foi retida a brônzea lança', importa verificar de quantas maneiras pode ser entendido o 'por ela ser parada'. A consideração das várias possibilidades [significativas] é procedimento oposto àquele de que fala Gláucon: alguns críticos partem de prevenida e absurda opinião, depois raciocinam concluindo pela censura, como se o poeta tivesse pensado algo de contraditório ao pressuposto deles." (ARISTÓTELES, Poética 1461a-31 - 1461b-3; 2000, p. 145; 1965, p. 46). ${ }^{10}$ O problema colocado por este verso, segundo N. J. Richardson, era o de que a lança

\footnotetext{
${ }^{9}$ Para uma informação complementar sobre estes três “sofistas" ver também o capítulo IV da segunda parte ("L'exégèse allégorique avant les Stö̈ciens") do livro Les mythes d'Homère et la pensée grecque de Félix Buffière (BUFFIÈRE, 1956, p. 123-136).

${ }^{10}$ Tradução de Eudoro de Souza, corrigida na citação de Homero e no seu entendimento (2000). Para o texto grego usamos a edição do Aristotelis De arte poetica liber de Rudolf Kassel para a coleção "Oxford Classical Texts" (1965).
} 
(de Enéias) atravessa duas camadas do escudo (de Aquiles) e é retida pela camada de ouro, que está, portanto, no centro, o que estaria em contradição com a expectativa de que o ouro estivesse do lado de fora. Não sabemos, porém, por Aristóteles qual era a interpretação de Gláucon para este verso (ou qual era sua solução para este problema). Há também a menção por Porfírio (nas Questões homéricas 1. 168) de um Glaucos (a ser plausivelmente corrigido por Gláucon, segundo Richardson) que, como Antístenes e Aristóteles, teria proposto uma solução para o problema da taça de Nestor: a de que Nestor seria o único a saber o truque para levantá-la, tomando as asas de cada lado do diâmetro. (Cf. RICHARDSON, 1975, p. 77). Estas duas informações possíveis sobre Gláucon deixam, pois, ver o quanto os problemas abordados por ele estavam distanciados de uma leitura alegórica.

Mas não saberemos jamais se "os muitos e belos pensamentos sobre Homero" de Íon seriam um comentário de tipo alegórico ou apenas de crítica textual (ainda que, é certo, genericamente um comentário como os de Metrodoro, Estesímbroto e Gláucon), já que Sócrates está sendo irônico também ao dizer a ele: "É claro, pois, que não te recusarás a mostrá-lo para mim", pois no diálogo ele jamais permite que Íon o faça, e quando Íon na imediata sequência se presta a fazê-lo com sua declaração vaidosa e autoconfiante de que "vale a pena ouvir como ele tem adornado bem Homero" (de modo a merecer até mesmo "ser coroado com uma coroa de ouro pelos Homéridas"), Sócrates diz que ainda arranjará tempo livre ( $\sigma \chi \supset \lambda \eta ́ v)$ para ouvi-lo (ou seja: que esta demonstração de Íon ficará para uma outra vez), mas que agora ele deve responder à questão sobre se sua competência é somente a respeito de Homero ou também a respeito de Hesíodo ou Arquíloco.

Assim, pois, como a sequência do diálogo deixará claro, a ironia de Sócrates está em propor uma definição da atividade do rapsodo em termos que, segundo o conceito socrático do "conhecer a fundo o pensamento do poeta", a tornam uma impossibilidade, e Íon se deixa levar desavisada e ingenuamente, por imaginar saber que tipo de operação cognitiva é designada por Sócrates como o "conhecer a fundo o" ou "ser intérprete do" "pensamento do poeta" ou ainda o "saber o que o poeta quer dizer", o que faz ver o quanto o problema de Í́n (ou o ponto em que ele se deixa capturar) é também o da interpretação da fala de Sócrates (ou o do entendimento do conceito socrático do saber). Mesmo que apoiado em uma descrição de F. M. Cornford (em The Origin of Attic Comedy) da oposição entre os tipos extremos e cômicos do Eiron ("o fingidor" ou "farsante") e do Alazon ("o fanfarrão") que parte mais da Ética a Nicômaco de Aristóteles do que de exemplos em Aristófanes, Jerald Ranta propõe (em “The Drama of Plato's 'Ion”'; Ranta 1967-1968) com alguma plausibilidade que o humor no conjunto do Íon poderia ser suscitado justamente pela apropriação destes dois tipos cômicos nas personagens de Sócrates e Íon. Do ponto de vista dramático (que em um diálogo platônico é tão importante quanto o da argumentação filosófica), poderíamos pensar que se Sócrates consegue capturar Íon com a sua ironia é porque ele faz de algum modo o papel do astucioso representado pejorativamente pelo tipo cômico do El $p \omega \nu$ ("o fingidor" ou "farsante") - ainda que sua ironia não vise enganar danosamente o seu interlocutor -, enquanto por sua vez Íon representaria ainda com mais precisão, dada a sua vaidade e autoconfiança excessivas (assim como a estupidez nelas implícita), o papel oposto 
e complementar do tipo também cômico do ở $\lambda \zeta \omega^{\prime}$ ("o fanfarrão"), que em momento algum duvida do seu saber e acaba tendo de reconhecer não possuir nenhuma arte. ${ }^{11}$

\section{REFERÊNCIAS}

\section{Textos antigos (EDições E TRADUÇões)}

ARISTÓTELES. Poética. Tradução, prefácio, introdução, comentário e apêndices de Eudoro de Souza. 6. ed. Lisboa: Imprensa Nacional-Casa da Moeda, 2000. [1ª edição, 1966].

ARISTOTELIS De arte poetica liber. Recognovit brevique adnotatione critica instruxit Rudolfus Kassel. Oxford: Oxford University Press, 1965. (Col. Oxford Classical Texts).

ARISTOTLE. Nicomachean Ethics. Translated by H. Rackham. Cambridge, Massachusetts/ London: Harvard University Press, 1982 [1ª edição, 1926]. (Col. The Loeb Classical Library).

ARISTOTLE. Problems II, XXII-XXXVIII; Rhetorica ad Alexandrum. Translated by W. S. Hett and H. Rackham. Cambridge, Massachusetts/London: Harvard University Press, 1965 [1 ${ }^{\mathrm{a}}$ edição, 1937]. (Col. The Loeb Classical Library).

PLATÃO. Sobre a inspiração poética (Íon) \& Sobre a mentira (Hipias Menor). Introdução, tradução e notas de André Malta. Porto Alegre: L\&PM, 2007.

PLATO. On Poetry: Ion, Republic 376e-398b, Republic 595-608b. Edited by Penelope Murray. Cambridge: Cambridge University Press, 1997. (Col. Cambridge Greek and Latin Classics).

${ }^{11}$ Para completar uma primeira investigação sobre a ironia (e também o cômico) no Íon seria necessário ainda comentar com cuidado o seu segundo exemplo característico (por que contendo uma pretensa auto-depreciação que se converte na afirmação literal da verdade de um saber genérico e não especializado) na seguinte fala de Sócrates (respondendo a Íon que acabou de dizer: "Me alegro em ouvi-los a vós, os sábios"): "Eu gostaria que tu estivesses dizendo uma verdade, Íon! Mas sábios, eu presumo, são certamente vós, rapsodos e atores, e aqueles cujos poemas vós cantais; eu não digo

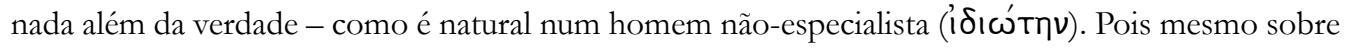

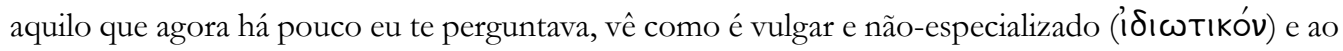
alcance de qualquer homem saber - que vale a mesma investigação, quando se toma uma arte como um todo." (Ion 532 d-e; 1997, p. 40). Seria, enfim, útil também considerar como exemplo possível de ironia socrática (onde não estaria ausente um sutil sarcasmo) - ainda que a auto-depreciação não seja aí um elemento explícito (mas apenas por contraste a alguém que é qualificado de divino) e o sentido outro ou contrário da proposição o seja - a teoria socrática da inspiração poética pela Musa, com toda a apropriação (aparentemente fascinada) de imagens tradicionais do êxtase ou possessão divina, apenas para justificar a proposição essencial de que um rapsodo especializado apenas em Homero como Íon (assim como um poeta especializado em apenas um gênero ou, cúmulo cômico como no caso de Tínico, em apenas um único bom poema) não pode possuir propriamente uma arte. 
PLATO. The Statesman - Pbilebus. Translation by Harold N. Fowler; Ion. Translation by W. R. M. Lamb. Cambridge, Massachusetts/London: Harvard University Press, 1995. [1 $1^{\mathrm{a}}$ edição, 1925]. (Col. The Loeb Classical Library).

PLATON. Oewures complètes tome V, $1^{\text {ire }}$ partie: Ion - Ménexène - Euthydème. Texte établi et traduit par Louis Méridier. Paris: Les Belles Lettres, 1989, Septième tirage. [1ª edição, 1931].

PLATON. Ion. Traduction, introduction et notes par Monique Canto. Paris: Flammarion, 1989.

TRATTATISTI GRECI: TEOFRASTO. Caratteri (a cura di Massimo Vilardo); ANONIMO, Il Sublime (a cura di Giulio Guidorizzi); GALENO, Sulle facoltà naturali (a cura di Marzia Montarino). Milano: Mondadori, 2008. (Col. I Classici).

\section{Textos modernos}

BUFFIÈRE, F. Deuxième partie, chapitre IV: L'exégèse allégorique avant les Stoïciens. In: . Les mythes d'Homère et la pensée grecque. Paris: Les Belles Lettres, 1956. p. 123-136.

LABARBE, J. Chapitre II - L'Ion. In: . L'Homère de Platon. Paris: Les Belles Lettres, 1949. p. 88-136.

NAGY, G. Homer and Plato at the Panathenaia. In: . Plato's Rhapsody and Homer's Music.

Washington: Center of Hellenic Studies - Cambridge Mass.: Harvard University Press, 2002. p. 9-35.

RANTA, J. The Drama of Plato's 'Ton'. Journal of Aesthetics and Art Criticism, v. 26, p. 219-229, 1967-1968.

RICHARDSON, N. J. Homeric professors in the age of sophists. Proceedings of the Cambridge Philological Society, n. 201, p. 65-81, 1975.

VLASTOS, G. Socratic Irony. Classical Quaterly, v. 37, p. 79-86, 1987. 